\title{
The effects of particulate and ozone pollution on mortality in Moscow, Russia
}

\author{
Boris Revich • Dmitri Shaposhnikov
}

Received: 6 April 2009 / Accepted: 23 November 2009/Published online: 29 December 2009

(C) The Author(s) 2009. This article is published with open access at Springerlink.com

\begin{abstract}
The objectives of this study were (1) to evaluate how acute mortality responds to changes in particulate and ozone $\left(\mathrm{O}_{3}\right)$ pollution levels, (2) to identify vulnerable population groups by age and cause of death, and (3) to address the problem of interaction between the effects of $\mathrm{O}_{3}$ and particulate pollution. Time-series of daily mortality counts, air pollution, and air temperature were obtained for the city of Moscow during a 3-year period (2003-2005). To estimate the pollution-mortality relationships, we used a log-linear model that controlled for potential confounding by daily air temperature and longer term trends. The effects of $10 \mu \mathrm{g} / \mathrm{m}^{3}$ increases in daily average measures of particulate matter $\leq 10 \mu \mathrm{m}$ in aerodynamic diameter $\left(\mathrm{PM}_{10}\right)$ and $\mathrm{O}_{3}$ were, respectively, (1) a $0.33 \%$ [95\% confidence interval (CI) $0.09-0.57]$ and $1.09 \%$ (95\% CI $0.71-1.47$ ) increase in all-cause non-accidental mortality in Moscow; (2) a $0.66 \%(0.30-1.02)$ and $1.61 \%(1.01-2.21)$ increase in mortality from ischemic heart disease; (3) a $0.48 \%(0.02-$ $0.94)$ and $1.28 \%(0.54-2.02)$ increase in mortality from cerebrovascular diseases. In the age group $>75$ years, mortality increments were consistently higher, typically by factor of $1.2-1.5$, depending upon the cause of death. $\mathrm{PM}_{10}$-mortality relationships were significantly modified by $\mathrm{O}_{3}$ levels. On the days with $\mathrm{O}_{3}$ concentrations above the 90th percentile, $\mathrm{PM}_{10}$ risk for all-cause mortality was threefold greater and $\mathrm{PM}_{10}$ risk for cerebrovascular disease mortality was fourfold greater than the unadjusted risk estimate.
\end{abstract}

\footnotetext{
B. Revich $\cdot$ D. Shaposhnikov $(\bowtie)$

Environmental Health Laboratory, Institute of Forecasting,

Russian Academy of Sciences,

Nakhimovsky Prospect 47,

Moscow 117418, Russia

e-mail: dshap@newmail.ru
}

Keywords Interaction · Moscow · Mortality - Ozone Particulate matter

\section{Introduction}

Epidemiological studies of the link between particulate matter with an aerodynamic diameter of less than $10 \mu \mathrm{m}$ $\left(\mathrm{PM}_{10}\right)$, ozone $\left(\mathrm{O}_{3}\right)$ and mortality rates in different cities have yielded a wide range of estimates, leading to disagreement about the magnitude of the relationships and the strength of the causal connection. Unfortunately, no direct epidemiological studies of health effects of $\mathrm{PM}_{10}$ and $\mathrm{O}_{3}$ have been conducted in the Russian Federation to date. The work presented here attempts to fill this gap.

In the pooled Clean Air for Europe (CAFÉ) database, site-specific relative mortality risks associated with a $10 \mu \mathrm{g} / \mathrm{m}^{3}$ increase in average daily $\mathrm{PM}_{10}$ concentration ranged from a negative risk of $-0.56 \%$ in Erfurt, Germany to as high as $2.49 \%$ in Huelva, Spain, and 3.30\% in Palermo, Italy. Allcause mortality risks per $10 \mu \mathrm{g} / \mathrm{m}^{3}$ increase in $\mathrm{O}_{3}$ (8-hour average measure) were also disparate: from $-0.17 \%$ in Amsterdam, the Netherlands and $-0.14 \%$ in London, UK to as much as $2.25 \%$ in Valencia, Spain (WHO 2004). In light of these large uncertainties, some researchers have argued that the effects of $\mathrm{PM}_{10}$ can be explained by correlated gaseous pollutants, weather, season, or the analytical model used ( $\mathrm{Li}$ and Roth 1995; Moolgavkar et al. 1995). However, other researchers have proposed that these seemingly conflicting findings could also result from variations across the populations, measurement error, and poor data quality (Bell et al. 2005).

The magnitude of the relative influence of season on health risks in Moscow, with its continental climate, may be illustrated by the following fact: the amplitude of winter to 
summer variations in non-accidental mortality, defined as the ratio of maximum of 30-day average values to minimum of 30-day average values of daily mortality reaches 26\% (Revich and Shaposhnikov 2008), while the magnitudes of $\mathrm{PM}_{10}$ and $\mathrm{O}_{3}$ effects on total mortality may reach $8 \%$ at most (estimated on the basis of concentrationresponse curves and maximal pollution levels). Thus, the amplitude of seasonal variations of mortality in Moscow is several fold greater than any pollutant-induced variation. This discrepancy indicates that adequate control for air temperature and season is essential in studies on the health effects of air pollutants. Traditional methods of adjustment for all seasonal patterns and longer term (secular) trends involve Poisson regressions with smooth functions (e.g., sinusoidal terms), regression splines, or generalized linear modeling (Samoli et al. 2001). Even after the deseasonalization of mortality data, the results of multiple regression models are often difficult to interpret because of multicollinearity among air pollutants and air temperature. For example, Sartor et al. (1995) hypothesized that most of excess deaths during the heat wave of 1994 in Belgium were likely attributable to elevated levels of $\mathrm{O}_{3}$ (instead of temperature). Such multicollinearity, along with using data outside the linear range of dependencies, has caused errors in the determination of risks of individual pollutants to human health (Keatinge and Donaldson 2001).

The aim of the study reported here was to access relationships between air pollution and mortality, unconstrained by temperature, seasonal factors, and secular trends.

\section{Materials and methods}

Data

The span of this time-series study was 3 consecutive years (2003-2005). Daily mortality, temperature, and $\mathrm{O}_{3}$ data were available across the entire time period, and $\mathrm{PM}_{10}$ data were available for the period March 21, 2003 to December 28, 2005. Average daily air temperatures were obtained from the Moscow State University weather station, and average and maximum daily measures of air pollution by $\mathrm{O}_{3}$ and $\mathrm{PM}_{10}$ were obtained from Moscow Environmental Monitoring.

Files of deaths were obtained from the Center of Demography and Human Ecology of Institute of Economic Forecasting of the Russian Academy of Sciences. The causes of death were reported in ICD-10 format (10th revision of International Classification of Diseases). Daily mortality counts were constructed for deaths from all nonaccidental causes (total morality minus external causes V00-Y98), ischemic heart disease and angina pectoris (IHD, codes I20-I25), and cerebrovascular diseases (CVD, codes I60-I69). Mortality data were available for all ages as well as specifically for age groups $60-74$ and $75+$ years. Although it is common in public health literature to study the age group $65+$, we were unable to stratify data for this age group. Therefore, in addition to performing analyses on the all-age group, we also specifically analyzed the age group $75+$ years. The input of this age group in allage mortality is still significant: this group contributes $42.7 \%$ to mortality from all non-accidental causes, $54.2 \%$ to IHD mortality, and $59.8 \%$ to CVD mortality. One should be aware that the share of males in this age group is only $28 \%$, because the average age at death for males in Russia is much lower than that for females. However, in this study, no distinction was made by sex.

\section{Statistical methods}

For each cause of death and for each age group, we used a generalized linear bivariate model to obtain the logrelative rates of increase in mortality with $\mathrm{PM}_{10}$ and $\mathrm{O}_{3}$ concentrations:

$$
\begin{aligned}
\log E\left(M_{t}\right)= & \text { Const }+\beta P M_{10 t}+\gamma O_{3 t}+S_{t}(\text { Temp }, 6) \\
& +Y_{t}(M, D F)
\end{aligned}
$$

where the log-transformed daily deaths were used to produce a normal distribution of the dependent variable; $E\left(M_{t}\right)$ is the expected number of deaths $M_{t}$ on day $t$; $S_{t}(T e m p, 6)$ is a smooth function of mean temperature on day $t$, which was modeled by natural cubic splines of temperature with 6 degrees of freedom, with continuous first derivatives between adjoining segments. This approximation adequately reflected the fundamental property of mortality/temperature curves, which had a minimum around $18^{\circ} \mathrm{C}$. The $Y_{t}(M, D F)$ is the smooth function of the natural logarithm of daily mortality, which models all longer term trends.

Function $Y_{t}$ was modeled as a weighted moving window average of $\log M_{t}$, with the width of the moving window equal to the number of degrees of freedom $D F$ :

$$
Y_{t}=\sum_{i=0}^{D F} w_{i} \log M_{t+i}
$$

If the size of vector $M_{t}$ is $N$ (which corresponds to the total number of days in the time-series), then Eq. 2 defines $N-D F$ components of vector $Y_{t}$. The weights $w_{i}$ in Eq. 2 were determined as a compromise between the positively defined smoothness of function $Y_{t}$ and its goodness of fit:

$\frac{\lambda}{\text { goodness of fit }}+\frac{1-\lambda}{\text { smoothness }} \rightarrow \min$

where $\lambda$ is a parameter, $0<\lambda<1$, which ultimately defines the degree of smoothing. The goodness-of-fit is 
inversely proportional to the sum of the residuals $\sum_{t=1}^{N-D F}\left(Y_{t}-\log M_{t}\right)^{2}$; while smoothness is inversely proportional to the sum of squares of the differences between the first derivatives, measured on each pair of subsequent days:

$\sum_{t=2}^{N-D F-1}\left(Y_{t+1}-2 Y_{t}+Y_{t-1}\right)^{2}$. Thus, condition (3) was rewritten as

$$
\begin{aligned}
& \lambda \sum_{t=1}^{N-D F}\left(Y_{t}-\log M_{t}\right)^{2} \\
& \quad+(1-\lambda) \sum_{t=2}^{N-D F-1}\left(Y_{t+1}-2 Y_{t}+Y_{t-1}\right)^{2} \\
& \quad \rightarrow \min
\end{aligned}
$$

where vector $Y_{t}$ is the function of $N$ values $M_{t}$, the width of moving window $D F$, and parameter $\lambda$. In our model, $D F=$ 182 (half a year) was chosen to reflect a general understanding of the time scale of the major possible confounders (long-term changes in health status, seasonal variations, influenza epidemics). Preliminary trials showed that the weights $w_{i}$ in Eq. 2 decrease rapidly as the index $i$ increases. The distribution $w(i)$ resembled a one-sided Gaussian distribution, and its half-width was inversely proportional to the parameter $\lambda$. By varying this parameter, we could easily select the desired amount of smoothness of the $Y_{t}$ function, which was used in the sensitivity analysis (as described in detail in the Results).

We analyzed the sensitivity of the regression results to the model assumptions, which were the choice of time lag between pollution and mortality, the choice of the seasonal smoothing algorithm, and the adjustment for mortalitytemperature dependency.

With respect to the choice of the smoothing algorithm, we conducted two types of sensitivity analysis. The first type of sensitivity analysis involved increases in the amount of smoothness by varying the parameter $\lambda$ in Eq. 4 from $10^{-4}$ to $10^{-6}$. In general, any increase in the amount of smoothness means that more information on the longer term effects is retained for subsequent risk calculations. When $\lambda$ was set to $10^{-4}$, the smoother of daily mortality had about 18 oscillations over the 3 -year study period, i.e., its quasi-period was equal to approximately 2 months on average. When $\lambda$ was set to $10^{-5}$, the smoother of daily mortality had nine oscillations in the 3 -year period, i.e., a quasi-period of approximately 4 months. When $\lambda$ was set to $10^{-6}$, the smoother of daily mortality had only three oscillations in the 3-year period, i.e., one quasi-period per annum. This was the maximum reasonable amount of smoothness because the resultant smoother reflected only winter-to-summer periodicity and contained no information on smaller time scales. Further increase in smoothness would mean almost no control for the temporal confounding of the daily mortality time series in the framework of Model (1). We also established that the amount of smoothness, as generated by appropriate choice of parameter $\lambda$, did not depend much upon the cause of mortality.

The second type of sensitivity analysis pertains to the choice of the analytical approach, which accounts for the longer term fluctuations of mortality with time. We compared the results of the approach developed in this paper with a more common method of partialling out slow fluctuations of mortality by including natural cubic splines of calendar time in Model (1). In this type of sensitivity analysis, our aim was to keep the amount of smoothness approximately the same.

The problem of interaction between $\mathrm{PM}_{10}$ and $\mathrm{O}_{3}$ was addressed in the following way. We stratified the data for high $\mathrm{O}_{3}$ levels and calculated $\mathrm{PM}_{10}$ risks in the framework of the univariate $\left(\mathrm{O}_{3}\right.$ removed) regression model only for those days with $\mathrm{O}_{3}$ levels above the 90th centile of the long-term distribution of daily mean $\mathrm{O}_{3}$. We called this risk estimate "adjusted". We then compared it to the "crude" $\mathrm{PM}_{10}$ risk estimate, i.e., calculated under the same model, but including all days of the study period. The symmetrical approach was used to determine whether high levels of $\mathrm{PM}_{10}$ could modify the $\mathrm{O}_{3}$ effect on mortality.

\section{Results}

Tables 1 and 2 show the selected descriptive statistics of distributions of daily mortality, air temperature, and air pollution in Moscow during the study period.

Table 3 shows the relative mortality risks attributed to $\mathrm{PM}_{10}$ and $\mathrm{O}_{3}$ as percentage increments of daily deaths per $10 \mu \mathrm{g} / \mathrm{m}^{3}$ of daily average measures of pollution.

All effects of pollution on mortality seemed to be immediate, rather than postponed. For particulates, the power of association was always greater at lag $=0$ than at the mean lag, and it rapidly diminished at lag $=1$. For $\mathrm{O}_{3}$, the power of association with the mean lag was generally higher, but the regression coefficients were not that sensitive to the variation in time lag (for an example, see Table 4 for all-cause non-accidental mortality). Based on the results of this sensitivity analysis, we chose same-day $\mathrm{PM}_{10}$ and mean lag $\mathrm{O}_{3}$ concentrations as predictors; both had the greatest explanatory power in the framework of the bivariate regression model (Model 1).

Table 5 compares the regression results for all-age nonaccidental mortality obtained under the constraints of Model (1) after application of the moving average smoother with varying degrees of smoothness. The risk estimates obtained were quite sensitive to the amount of smoothness. The smoother with $\lambda=10^{-4}$ generated the best estimate of log- 
Table 1 Descriptive statistics of daily mortality (number of deaths)

${ }^{a}$ Standard deviation and percentage relative error

\begin{tabular}{llllll}
\hline Cause of death & Age group & Minimum & Maximum & Mean & SD (PRE) \\
\hline All non-accidental causes & All ages & 255 & 586 & 331.2 & $30.4(9)$ \\
& $75+$ & 91 & 302 & 141.3 & $18.5(13)$ \\
Ischaemic heart disease & All ages & 73 & 229 & 114.5 & $15.3(13)$ \\
& $75+$ & 29 & 147 & 62.1 & $10.5(17)$ \\
Cerebrovascular diseases & All ages & 35 & 142 & 68.8 & $10.9(16)$ \\
& $75+$ & 16 & 85 & 41.0 & $8.1(20)$ \\
\hline
\end{tabular}

relative $\mathrm{PM}_{10}$ rate in terms of its statistical significance. In this case, only the information from time scales shorter than approximately 2 months was used to estimate the regression coefficients $\beta$ and $\gamma$. The increase in smoothness resulted in the loss of statistical significance of $\mathrm{PM}_{10}$ rate, while the $\mathrm{O}_{3}$ rate noticeably increased, and its statistical significance improved. This trend was the same for all analyzed categories of mortality, and most probably relates to the seasonality of $\mathrm{O}_{3}$ risks, as observed by Bates (2005) and other authors (see Discussion). We conclude that the smoother with $\lambda=10^{-4}$ is the preferred value to effectively eliminate confounding from seasonal effects and adequately describe short-term effects of both particulate matter and $\mathrm{O}_{3}$.

Having chosen the appropriate amount of smoothness, we then compared the smoother developed in our study with the natural cubical spline of time with 6 degrees of freedom per year, which has been used, for example, in the National Morbidity, Mortality, and Air Pollution Study (USA: NMMAPS) (Daniels et al. 2004). Both smoothers produced about the same amount of smoothness and differed only in analytical methods of their construction. The results of sensitivity analysis (not shown here) proved that both algorithms appropriately converged and produced the equivalent results in terms of statistical significance and magnitude of $\mathrm{PM}_{10}$-mortality and $\mathrm{O}_{3}$-mortality risks.

Disregard for the mortality-temperature relationship [i.e., assumption that $S_{t}($ Temp, 6) $=0$ in Eq. 1] led to an overestimation of the $\mathrm{PM}_{10}$-mortality and $\mathrm{O}_{3}$-mortality risks. The risks in all categories of mortality increased by $20-30 \%$. For example, the increases in non-accidental mortality in the age group $75+$ years that were associated with $10 \mathrm{mkg} / \mathrm{m}^{3}$ increases in $\mathrm{PM}_{10}$ and $\mathrm{O}_{3}$ levels were 0.69 (95\% CI 0.35 $1.03)$ and 1.57 (95\% CI 1.01-2.13), respectively, if the mortality was not adjusted for air temperature (compare with corresponding values in Table 3).

The results of our tests for interaction between the effects of particulate and $\mathrm{O}_{3}$ pollution on mortality are summarized in Table 6, which compares crude and adjusted $\mathrm{PM}_{10}$ risks calculated under the univariate regression model. Crude $\mathrm{PM}_{10}$ risks in Table 6 slightly differ from those in Table 3. This difference can be explained by the difference between univariate and bivariate regressions. As Table 6 shows, the adjusted $\mathrm{PM}_{10}$ risks in all six categories of mortality were noticeably greater than the crude risks, which we could not attribute to a mere chance. The correlation between adjusted and crude risk estimates may be described in the following way: if the six ratios $\beta_{\text {adj }} / \beta_{\text {crude }}$ in Table 6 were randomly selected from an underlying normal distribution, then their mean of 3.2 (95\% CI 2.1-4.3) significantly differs from 1 (one-sample $t$-test $P=.003$ ). Therefore, we presumed the existence of a mechanism that amplified the $\mathrm{PM}_{10}$ rate in the presence of high concentrations of $\mathrm{O}_{3}$. For example, on the days with $\mathrm{O}_{3}$ concentrations above the 90th percentile, $\mathrm{PM}_{10}$ risks for all-cause mortality in both age groups were roughly threefold greater and $\mathrm{PM}_{10}$ risks for cerebrovascular disease mortality were fourfold greater than unadjusted risk estimates.

Although four of the six adjusted risk estimates in Table 6 were statistically significant at 95\% level, the differences between adjusted and crude risks were not significant, which could be proved by calculation of the standard errors of the differences. In our opinion, such a lack of significance may be explained by the small number of observations in the adjusted samples (we used $90 \%$ percentile of $\mathrm{O}_{3}$ concentrations as a cut-off point, which left only 100 days).
Table 2 Descriptive statistics of air temperature and air pollution

$\mathrm{PM}_{10}$, Particulate matter $\leq 10 \mu \mathrm{m}$ in aerodynamic diameter

\begin{tabular}{llll}
\hline Values & Temperature $\left({ }^{\circ} \mathrm{C}\right)$ & $\mathrm{PM}_{10}\left(24-\mathrm{h} \mu \mathrm{g} / \mathrm{m}^{3}\right.$ measures $)$ & $\mathrm{O}_{3}\left(24-\mathrm{h} \mu \mathrm{g} / \mathrm{m}^{3}\right.$ measures $)$ \\
\hline Minimum & -24.6 & 9 & 4 \\
Mean & 6.4 & 34 & 23 \\
$90 \%$ centile & 19.4 & 53 & 41 \\
Maximum & 24.7 & 164 & 73 \\
\hline
\end{tabular}


Table 3 Relative mortality increments per $10 \mu \mathrm{g} / \mathrm{m}^{3}$ increase in $\mathrm{PM}_{10}$ and $\mathrm{O}_{3}$

${ }^{\mathrm{a}}$ Mean increments are expressed as a percentage per $10 \mu \mathrm{g} / \mathrm{m}^{3}$, with the $95 \%$ CI given in parenthesis and the $P$ value. $\mathrm{PM}_{10}$ is measured on the same day; $\mathrm{O}_{3}$ is averaged over the same and previous day

\begin{tabular}{llll}
\hline Cause of death & Age group & \multicolumn{2}{l}{ Mean increment ${ }^{\mathrm{a}}$} \\
\cline { 3 - 4 } & & $\mathrm{PM}_{10}$ & $\mathrm{O}_{3}$ \\
\hline All non-accidental causes & All ages & $0.33(0.09-0.57) P=0.006$ & $1.09(0.71-1.47) P<0.001$ \\
& $75+$ & $0.55(0.21-0.89) P=0.002$ & $1.24(0.68-1.80) P<0.001$ \\
Ischemic heart disease & All ages & $0.66(0.30-1.02) P<0.001$ & $1.61(1.01-2.21) P<0.001$ \\
& $75+$ & $0.81(0.31-1.31) P=0.001$ & $1.88(1.08-2.68) P<0.001$ \\
Cerebrovascular diseases $P$ & All ages & $0.48(0.02-0.94) P=0.035$ & $1.28(0.54-2.02) P=0.001$ \\
& $75+$ & $0.72(0.14-1.30) P=0.014$ & $1.25(0.31-2.19) P=0.008$ \\
\hline
\end{tabular}

Table 4 The effects of a $10 \mu \mathrm{g} / \mathrm{m}^{3}$ increase in $\mathrm{PM}_{10}$ and $\mathrm{O}_{3}$ on all-cause non-accidental mortality, percentage increases in mortality per $10 \mathrm{mkg} /$ $\mathrm{m}^{3}$ increase in pollutant concentrations, at different time lags between changes in pollution and changes in mortality

\begin{tabular}{|c|c|c|c|c|c|c|}
\hline \multirow[t]{2}{*}{ Measures } & \multicolumn{3}{|l|}{$\mathrm{PM}_{10}$} & \multicolumn{3}{|l|}{$\mathrm{O}_{3}$} \\
\hline & Lag 0 & Mean lag & Lag 1 & Lag 0 & Mean lag & Lag 1 \\
\hline Mean increase, $\%(95 \% \mathrm{CI}) t$ test & $\begin{array}{l}0.33(0.09- \\
0.57) t=2.8\end{array}$ & $\begin{array}{l}0.30(0.04- \\
0.56) t=2.3\end{array}$ & $\begin{array}{r}0.18(-0.06- \\
0.42) t=1.5\end{array}$ & $\begin{array}{c}0.98(0.62- \\
1.34) t=5.5\end{array}$ & $\begin{array}{c}1.09(0.71- \\
1.47) t=5.7\end{array}$ & $\begin{array}{l}0.92(0.56- \\
1.28) t=5.2\end{array}$ \\
\hline
\end{tabular}

Table 5 The results of the sensitivity analysis with respect to the amount of smoothness and percentage increases in all-age non-accidental mortality per $10 \mathrm{mkg} / \mathrm{m}^{3}$ increase in pollutant concentrations

\begin{tabular}{|c|c|c|c|c|c|c|}
\hline \multirow{2}{*}{$\begin{array}{l}\text { Analysis } \\
\text { Smoothing parameter } \\
\text { in Eq. } 4\end{array}$} & \multicolumn{6}{|c|}{ Degree of smoothing } \\
\hline & $\lambda=10^{-4}$ & & $\lambda=10^{-5}$ & & $\lambda=10^{-6}$ & \\
\hline $\begin{array}{l}\text { Characteristic period of } \\
\text { smoother oscillations }\end{array}$ & 2 months & & 4 months & & 1 year & \\
\hline Pollutant & $\mathrm{PM}_{10}$ & $\mathrm{O}_{3}$ & $\mathrm{PM}_{10}$ & $\mathrm{O}_{3}$ & $\mathrm{PM}_{10}$ & $\mathrm{O}_{3}$ \\
\hline $\begin{array}{c}\text { Mean increase, } \% \\
(95 \% \text { CI } t \text { test }\end{array}$ & $\begin{array}{l}0.33(0.09- \\
0.57) t=2.8\end{array}$ & $\begin{array}{l}1.09(0.71- \\
1.47) t=5.7\end{array}$ & $\begin{array}{l}0.29(0.03- \\
0.55) t=2.2\end{array}$ & $\begin{array}{l}1.58(1.16- \\
2.00) t=7.6\end{array}$ & $\begin{array}{r}0.21(-0.05- \\
0.47) t=1.5\end{array}$ & $\begin{array}{l}1.81(1.35- \\
2.27) t=8.0\end{array}$ \\
\hline
\end{tabular}

Table 6 Relative mortality increments per $10 \mu \mathrm{g} / \mathrm{m}^{3}$ increase in $\mathrm{PM}_{10}$, adjusted for $\mathrm{O}_{3}$ concentrations above the 90th percentile

\begin{tabular}{|c|c|c|c|c|}
\hline Cause of death & Age group & $\beta_{\text {crude }}$ & $\beta_{a d j}$ & $\beta_{\text {adj }} / \beta_{\text {crude }}$ \\
\hline \multirow[t]{2}{*}{ All non-accidental deaths } & All ages & $0.27(0.03-0.51)^{*}$ & $0.99(0.09-1.89)^{*}$ & 3.7 \\
\hline & $75+$ & $0.52(0.18-0.86)^{*}$ & $1.41(0.11-2.71)^{*}$ & 2.7 \\
\hline \multirow[t]{2}{*}{ Ischemic heart disease } & All ages & $0.58(0.20-0.96)^{*}$ & $1.45(-0.31-3.21)$ & 2.5 \\
\hline & $75+$ & $0.72(0.22-1.22)^{*}$ & $1.33(-1.17-3.83)$ & 1.8 \\
\hline \multirow[t]{2}{*}{ Cerebrovascular diseases } & All ages & $0.40(-0.06-0.86)$ & $1.8(0.0-3.6)^{*}$ & 4.5 \\
\hline & $75+$ & $0.64(0.06-1.22)^{*}$ & $2.6(0.4-4.8)^{*}$ & 4.1 \\
\hline
\end{tabular}

*Statistically significant at the $95 \%$ level

Values are given in percentages, with the $95 \%$ CI given in parenthesis

$\beta$ is a regression coefficient (adj, adjusted) 


\section{Discussion}

The approach developed in this paper provided a sufficient burden of evidence to establish relationships between particulate and $\mathrm{O}_{3}$ pollution in Moscow, on the one hand, and the selected health endpoints on the other. All health risk estimates were statistically significant $(P<0.05)$. Based on these results, we conclude that $\mathrm{PM}_{10}$ and $\mathrm{O}_{3}$ concentrationresponse coefficients in Moscow largely agree with the results of previous research in other countries. We arrived at an estimate of $\mathrm{PM}_{10}$ rate of $0.33 \%$, which is very close to the value obtained in meta-analyses of 26 European studies $(0.40 \%)$ and 20 of the largest U.S. cities $(0.28 \%)$, which did not use generalized additive model (GAM) methods (WHO 2004; Daniels et al. 2004). Our estimate of association between non-accidental mortality and $\mathrm{O}_{3}$ in Moscow (1.09\%) was somewhat higher than both the corresponding APHEA (Air Pollution and Health-A European Approach) estimate for European cities with a high standardized mortality rate $(0.48 \%)$ and the NMMAPS estimate (0.44\%) (Gryparis et al. 2004; Bell et al. 2005). The differences between the estimates should of course be viewed in light of their confidence limits.

When our estimates are compared with the results of foreign studies, one should be aware that climate clearly affects the estimates of pollution/mortality relationships. Moderate climates tend to be associated with lower risks of $\mathrm{PM}_{10}$ and $\mathrm{O}_{3}$ than sub-tropical climates. For example, the cited WHO report (2004) states that such southern cities as Athens, Barcelona, Milan, and Tel Aviv have relatively high unit risks of $\mathrm{PM}_{10}(1.55,0.93,1.17$, and $0.64 \%$, respectively), with all of these values being statistically significant at the $95 \%$ level. In comparison, northern cities, such as Helsinki, Prague, Stockholm, and Amsterdam, have lower unit risks of $\mathrm{PM}_{10}(0.32,0.12,0.39$, and $0.27 \%$, respectively), and all of these values are non-significant-i.e., the lower limits of the $95 \%$ confidence intervals are all negative. Similarly, Bates (2005) pointed out that, based on his analysis of $\mathrm{O}_{3}$ and mortality in 23 cities or regions all over the world, the two cities least likely to be confounded by seasonality (Brisbane and Mexico City) gave the highest response outcome-about $1.75 \%$ per $10 \mu \mathrm{g} / \mathrm{m}^{3} 24-\mathrm{h} \mathrm{O}_{3}$. The risks of $\mathrm{O}_{3}$ in these two cities, unconfounded by seasonality because of their tropical climate, were several fold higher than those in Northern cities, which had distinct "ozone seasons" (values for the latter were, on average, $0.43 \%$ per $10 \mu \mathrm{g} / \mathrm{m}^{3}$ 24-h $\mathrm{O}_{3}$ ). Many authors explain the observed seasonality in $\mathrm{O}_{3}$ risks in moderate climates by the photochemical nature of $\mathrm{O}_{3}$ formation, which generally leads to higher levels of $\mathrm{O}_{3}$ in the summer than in winter. Gryparis et al. (2004) summarized data from 23 European regions and concluded that there was no association between $\mathrm{O}_{3}$ and mortality during the winter months. Ito et al. (2004) provided a detailed seasonal breakdown of data from eight U.S. regions, eight European cities, two Australian cities, plus Mexico City, Sao Paulo, Santiago, and two regions of South Korea, and showed that the main effect occurred in the warm season. In our research, the adjustment of mortality rates for seasonality and mortality-temperature relationships within the framework of Model (1) provided an alternative to stratification of pollution risks by season. This could probably explain why our estimates of $\mathrm{O}_{3}$ risks were higher than those typically reported for moderate climates.

In terms of the stratification of pollution risks by age groups, our analysis of short-term associations between particulate matter and mortality proved that larger effects were consistently observed for the elderly. Considering the share of the elderly population in the total-mortality category, nearly all $\mathrm{PM}_{10}$-induced increases in all-age mortality should be attributed to the excess deaths in this age group. In contrast, $\mathrm{O}_{3}$ risks are more evenly distributed between the two age groups, and the mean estimate for CVD death rate among the elderly is even lower than among the all-ages category.

Our estimates showed that the increases in cardio-vascular mortality were definitely higher than the risks of total nonaccidental mortality, which indicated that cardio-vascular deaths constituted the dominant share of pollution-related mortality.

Our tests for interaction with high $\mathrm{O}_{3}$ levels proved that linear Model (1) does not hold true at very high concentrations of $\mathrm{O}_{3}$, where $\mathrm{PM}_{10}$ regression coefficients tend to increase with co-pollutant level.

We found no evidence of $\mathrm{PM}_{10}$ being a modifier of the $\mathrm{O}_{3}$ effect on mortality. This result agrees with the observation of Gryparis et al. (2004), who studied potential modifiers of the $\mathrm{O}_{3}$ effect in 23 European cities and found out that the associations of total mortality with $\mathrm{O}_{3}$ levels were independent of $\mathrm{SO}_{2}$ and $\mathrm{PM}_{10}$. The same conclusion was confirmed in the NMMAPS study: the $\mathrm{O}_{3}$-induced risks of total, cardiovascular and respiratory mortality were insensitive to the adjustment for particulate matter (Bell et al. 2005).

Acknowledgements Mortality data were obtained from Dr. T. Khorkova from Center of Demography and Human Ecology of Institute of Forecasting. Meteorology data were provided by Prof. A. Isaev and his colleagues from the weather station of Moscow State University. We thank E. Semutnikova and her colleagues from Moscow Environmental Monitoring, who provided air pollution data for this research, and V. Ozheredov from Space Research Institute for analytical assistance.

Open Access This article is distributed under the terms of the Creative Commons Attribution Noncommercial License which permits any noncommercial use, distribution, and reproduction in any medium, provided the original author(s) and source are credited. 


\section{References}

Bates D (2005) Ambient ozone and mortality. Epidemiology 16:427-429

Bell M, Dominici F, Samet J (2005) A meta-analysis of ozone and mortality with comparison to the national morbidity, mortality, and air pollution study. Epidemiology 16:436-445

Daniels M, Dominici F, Zeger S, Sammet J (2004) The national morbidity, mortality, and air pollution study. Part III: $\mathrm{PM}_{10}$ concentration-response curves and thresholds for the 20 largest US cities. Research report. Health Effects Institute, Boston

Gryparis A et al (2004) Acute effects of ozone on mortality from the "Air pollution and health: a European approach" project. Am J Respir Crit Care Med 170:1080-1087

Ito K, DeLeon SF, Lippmann M (2004) Associations between ozone and daily mortality: analysis and meta-analysis. Epidemiology $16: 446-457$

Keatinge WR, Donaldson GC (2001) Mortality related to cold and air pollution in London after allowance for effects of associated weather patterns. Environ Res 86:209-216
Li Y, Roth HD (1995) Daily mortality analysis by using different regression models in Philadelphia County, 1973-1990. Inhal Toxicol 7:45-58

Moolgavkar SH, Luebeck EG, Hall TA, Anderson EL (1995) Particulate air pollution, sulfur dioxide, and daily mortality: a reanalysis of the Steubenville data. Inhal Toxicol 7:35-44

Revich B, Shaposhnikov D (2008) Temperature-induced excess mortality in Moscow, Russia. Int J Biometeorol 52:367-374

Samoli E, Schwartz J, Wojtyniak B, Touloumi G, Spix C, Balducci. F, Medina S, Rossi G, et al (2001) Investigating regional differences in short-term effects of air pollution on daily mortality in the APHEA project: a sensitivity analysis for controlling of long-term trends and seasonality. Environ Health Perspect 109:349-353

Sartor F, Snacken R, Demuth C, Walkiers D (1995) Temperature, ambient ozone levels, and mortality during summer 1994, in Belgium. Environ Res 70:105-113

WHO (2004) Meta-analysis of time-series studies and panel studies of particulate matter (PM) and ozone (O3). Document EUR/04/ 5042688. WHO Regional Office for Europe, Copenhagen 